\title{
WASH in schools for student return during the COVID-19 pandemic
}

Laura Bolton

IDS

February 2021

\section{Question}

How can WASH in schools be effective in re-opening schools and keeping schools open during the COVID-19 global pandemic? What are the critical factors for success in low and lower-middle income countries?

\section{Contents}

1. Summary

2. Introduction

3. Key WASH guidelines for practices in schools

4. Behaviour change

5. Measures to accompany WASH for school re-opening

6. References

The K4D helpdesk service provides brief summaries of current research, evidence, and lessons learned. Helpdesk reports are not rigorous or systematic reviews; they are intended to provide an introduction to the most important evidence related to a research question. They draw on a rapid deskbased review of published literature and consultation with subject specialists. 


\section{Summary}

The literature on WASH and school re-opening during the COVID-19 pandemic is dominated by guidelines with little in the way of recent evidence or lessons learned. Analysis of data from school re-openings at the end of 2020 suggests that with mitigation measures in place community infection rates should not be affected by children returning to school (UNICEF, 2020a). Although children carry lower risk of infection, they do have large numbers of contact in the school environment so hygiene and distancing measures are important.

The key guidelines for WASH in schools during the COVID-19 pandemic:

- Children and all school staff must be educated with regards to hand hygiene.

- Hand hygiene stations must be provided at entrances and exits.

- Hand washing must be frequent and requires sufficient water and soap.

- School buses should have hand hygiene measures in place.

- The school environment must be disinfected daily.

A number of options for installing handwashing facilities in low-income countries are available outlined in section 3 . These include tippy-taps, a bucket with a tap, conventional taps, a valve fitted to a bottle, bucket and cup, and a camp sink.

Lessons learned on promoting hand hygiene during the pandemic (not specific to schools) include:

- Pre-pandemic knowledge on hygiene behaviour change is relevant.

- Disease information alone is insufficient to change behaviour.

- Investing in hand washing facilities ensures greater success.

- Systematic programme design using a behaviour change framework is still possible during outbreaks.

Environmental, or nudge-based, cues are recommended to support behaviour change in children based on pre-COVID-19 evidence. Examples include colourful footprints leading to a handwashing facility, images of eyes above handwashing facilities, embedding toys in soap, and putting pictures of germs on surfaces.

Measures to accompany WASH for successful school re-opening include:

- Sharing of age-appropriate information on symptoms to look out for (as well as hygiene).

- Reducing physical contact.

- Ventilation and mask-use (for over 5's).

- Contact tracing in line with national policies and clear protocols for re-closure.

UNICEF (2020b) state that specific WASH measures supporting the COVID-19 response can support girls and vulnerable groups. For example return to school campaigns in Burkina Faso are raising awareness for girl's education and offering scholarships and school meals for the most vulnerable. The only other vulnerable group mentioned are students with disabilities and only examples in high-income countries. 


\section{Introduction}

Worldwide the education of an estimated 1.54 billion children has been affected by the COVID19 pandemic (Global Education Cluster, 2020). School closures are risking children's health and wellbeing with negative impacts on learning outcomes and welfare (UNICEF \& WHO, 2020a). Early research findings ${ }^{1}$ suggest that children are at lower risk of contracting COVID-19 than adults. However, children are still able to catch it and are potential transmitters of the virus (Watson, 2020). The decision to re-open a school must be guided by a risk-based approach taking local epidemiology into account (WHO, UNESCO \& UNICEF, 2020). Analysis of data at the end of 2020 from 191 countries finds that re-opening of schools with mitigation measures in place has not affected community infection rates or increased risks for teachers (UNICEF, 2020a).

Although there are less cases among children, a number of factors make spread more likely. These include the large number of contacts children have at school and a higher tendency to put their hands in their mouth (CDC, 2020). International guidelines emphasise the importance of hygiene in schools to reduce transmission.

One report found that 50 percent of countries identified as at risk from COVID-19 lacked basic water and sanitation services (UNICEF \& WHO, 2020a). "Accelerating progress in countries with the lowest coverage of WASH in schools will therefore be critical to improve school safety during the COVID-19 pandemic and beyond" (p6). It is a large-scale challenge for some countries to bring hygiene standards up but an important opportunity to make improvements for the future.

The three main goals for minimising COVID-19 spread with school re-opening are: 1) reducing transmission between people, 2) reducing contact exposure, and 3) ensuring those with symptoms stay at home (Watson, 2020).

\section{Key WASH guidelines for practices in schools}

All school staff and students need to be educated with regards to hand hygiene, respiratory etiquette, mask use, and recognising symptoms (WHO, 2020). Orientation training is needed for all staff and community members so that they are aware of their specific role (WASH in Schools Network, 2020a). Messaging and communication should be used to counter rumours and misleading information (WHO, UNESCO \& UNICEF, 2020). Core messages for children are when to wash hands, how to cover mouth when sneezing or coughing, to tell someone when you feel unwell, and not to touch others when greeting (WASH in Schools Network, 2020b).

Hand hygiene stations should be provided at entrances and exits. Washing hands with soap is a powerful hygiene behaviour but must be done regularly and habitually at critical times (UNICEF \& GIZ, 2016). Hand washing stations must be spread out sufficiently for social distancing (WASH in Schools Network, 2020a).

Hand hygiene must be frequent and a schedule is recommended (WHO, UNESCO \& UNICEF, 2020). Water is needed for handwashing and where increased water storage capacity is needed,

${ }^{1}$ https://www.ucl.ac.uk/news/2020/may/children-appear-half-likely-catch-covid-19-adults 
help may be sourced from the community or children could be asked to bring in bottled water from home (WASH in Schools Network, 2020a). A timetable for handwashing should be set around arrival, breaks and lunch (WHO, 2020). For supplies and usage Save the Children (2020a) suggest considering ten handwashes per person per day.

School buses should follow hand hygiene measures, respiratory guidelines, and physical distancing (WHO, 2020).

School environment and transport must be disinfected daily including all frequently touched surfaces with a checklist for cleaners (WHO, 2020). Items that cannot be cleaned should not be shared. The WASH in Schools Network provides a suggested checklist including checks for entrances, classrooms, and toilets (WASH in Schools Network, 2020c). Cleaning supplies must include disinfectant with household bleach diluted to $0.1 \%$ or alcohol-based disinfectants with at least 70\% alcohol concentration (WASH in Schools Network, 2020a). A list of item requirements for cleaning including suggested amounts, are listed in a Save the Children kit list (Save the Children, 2020b). Community members can be involved to help with cleaning if required. All staff and community members must be trained in the cleaning procedures required. Water availability is important for cleaning purposes (Global Education Cluster, 2020).

A monitoring team should be established to oversee maintenance issues, soap availability, and adherence to recommended behaviours (WASH in Schools Network, 2020a).

\section{Evidence and experience}

UNICEF (2020b) report successful implementation of context-appropriate health and hygiene protocols in a number of low- and middle-income countries during the current pandemic including Algeria, Belize, Botswana, Cambodia, Cameroon, Indonesia, Madagascar, Mexico, Tanzania, Ukraine. Measures include a combination of "school cleaning and disinfecting, improving handwashing facilities, provision of cleaning and hygiene supplies to schools, and health checks and related communication messages for children and community members" (UNICEF, 2020b, p3). Limited details are described for individual countries in the report. In Côte d'Ivoire, hand washing facilities have been installed, and protective equipment provided for teachers.

Mitigation measures must be taken seriously. The only case where a school was identified as superspreading was one in Jerusalem, Israel where mitigation measures were not followed (UNICEF, 2020a).

An impact review of WASH interventions pre-COVID-19 identifies a number of studies that found positive correlations with reductions in diseases such as diarrhoea (McMichael, 2019). Contrasting assessments were also found where WASH had no statistically significant effect on disease-related outcomes. The review was unable to make conclusions about why interventions worked or did not work although political will and programme fidelity are thought to be key.

\section{Handwashing facility options}

A compendium on low-cost hand-washing facilities for low-income settings describes methods, advantages, disadvantages and accessibility (Coultas, lyer, and Myers, 2020). Technologies include: 
- Tippy taps. A simple container filled with water which flows when tipped. It can be operated with a foot pedal.

- A bucket or container with a tap. Ideally the water container should be closed or fitted with a lid.

- Conventional taps with or without a basin. If the tap is over open ground a container should collect wastewater or stones placed underneath to assist drainage.

- HappyTap/LaBobo. A portable handwashing facility.

- Valve/tap fitted bottle. A tap or valve is fitted to a plastic bottle.

- Bucket and cup. A larger water container with a smaller container to scoop and pour water for handwashing.

- Camp sink. Two buckets stacked on top of each other, one with wastewater and one with fresh water operating with a pump system.

A publication prepared for Fit Schools International provides a number of examples of scaling up group handwashing in schools (UNICEF \& GIZ, 2016). Key design features are described and considerations for construction, operation, maintenance and cost. Examples include a tippy tap facility in Nigeria, a metal basin and attached bucket in India, a pre-fabricated wash facility assembled by a school in Cambodia, a punched PVC pipe over a rain gutter in Cambodia, semiautomatic refillable buckets in Lao, a brick facility with gravel drainage in Zambia, and a washing facility with rainwater harvesting in Indonesia.

WASHaLOT is a pre-fabricated handwashing system able to service a number of individuals at a time (GIZ \& Sustainable Sanitation Alliance, 2020). The water carrying pipe can be filled manually or connected to a piped supply. It is easy to operate and maintain as it has wide openings at both sides and at the bottom of the pipes. The school community are engaged in the installation and maintenance.

Contactless handwashing stations are available for reducing the touching of shared surfaces. An example is shown in Nepal by WaterAid (2020) ${ }^{2}$.

Factsheets, posters and comic books are available for supporting hygiene messages in WASH in Schools Network (2020b).

\section{The Three Star Approach}

The Three Star Approach for WASH in schools gives guidelines for hygiene practices and acts as a monitoring system to incentivise permanent change (UNICEF \& GIZ, 2013). Simple inexpensive steps are designed so that all students wash their hands with soap, have access to drinking water and are provided with clean, gender-segregated toilets. Schools start by achieving minimum standards and then expand to higher star-ratings for hygiene promotion and improving infrastructure, especially for girls. Three Star guides help to advise on facilities that are needed, construction of group washing facilities, hygiene supplies, storing soaps and sanitary pads, hygiene information, menstrual hygiene management, key hygiene messages to emphasise, and

\footnotetext{
${ }^{2}$ https://www.wateraid.org/sites/g/files/jkxoof271/files/2020-04/wateraid-nepal-technical-briefcontactless\%20handwashing-stations.pdf
} 
school-based management for repair and maintenance (Philippines Department of Education, 2018).

\section{Behaviour change}

A learning brief draws together lessons for promoting handwashing in all contexts gathered during the pandemic (COVID-19 HygieneHub, 2020). Key lessons include:

- Pre-pandemic knowledge on hygiene behaviour change is relevant.

- Disease information alone is insufficient to change behaviour. Behavioural determinants should be identified and promotion activities designed to directly address barriers.

- Investing in hand washing facilities ensures greater success. Prioritise improving access to convenient and desirable handwashing facilities.

- Systematic programme design using a behaviour change framework is still possible during outbreaks.

- Create a monitoring and evaluation strategy early on. Programme adaptation is necessary on an ongoing basis. Regularly discuss the programme with stakeholders and users.

A report from the WASH in Schools Network (WinS) recommends a number of nudge-based interventions to help cue handwashing to reduce the spread of COVID-19 (Watson \& Dreibelbis, 2020). Environmental nudges are defined in the report as "small changes to the environment that alter behaviour in a predictable way but do not explicitly constrain choices" (p3) and can be used to cue and trigger hand washing with soap for school children. Knowledge and intention are found to be poor predictors of behaviour change as actions are not necessarily based on rational thinking (White et al., 2020). Environmental cues trigger automated response with minimal conscious engagement and are therefore recommended to improve behaviour change.

Nudges should be one component of a larger strategy, and are an interim measure (Watson \& Dreibelbis, 2020). More comprehensive strategies are needed to ensure handwashing is incorporated into routines and becomes an improved habit. Availability of, and accessibility to water and soap is required before nudge-based interventions.

Ways of influencing handwashing with nudges includes improving the functional design of objects, improving the aesthetics of the surroundings, altering presentation of facilities and dispensers, applying labels or endorsement information, and altering the positioning of objects. Interventions should make the behaviour easy, attractive, social, timely, and inclusive.

Considerations for designing nudges:

- Which types of colours, designs, and messages would be eye-catching and engaging?

- Make sure targets are appropriate for your users.

- Make use of available resources.

- Different designs are more conducive to different environments. 
- Nudges will require maintenance, repair, or reinstallation.

\section{Examples and evidence on environmental nudges and handwashing behaviour change} pre-COVID-19 (Watson \& Dreibelbis, 2020):

- Colourful footprints leading to the handwashing facility. This was found to increase handwashing behaviour in a school in Bangladesh by 64 percent (Dreibelbis et al., 2016). This intervention has been found to be equally as effective as a high-intensity educationbased intervention whilst using less resources (Grover et al., 2018).

- Images of eyes above handwashing facilities. A study in India found women to be 10 percent more likely to wash their hands with this intervention in place than without (Biran et al., 2014).

- Embedding toys in soap so that children are incentivised to use it. Children in a displacement camp in Iraq were found to be four times more likely to wash their hands with this intervention (Watson et al, 2019).

- Putting pictures of germs on surfaces to induce disgust and remind of hidden dangers.

- Placing mirrors can draw people to hand washing stations and increase the likelihood of handwashing.

\section{Measures to accompany WASH for school re-opening}

Schools should share age-appropriate information on COVID-19 symptoms and hygiene. Younger children learn best through play with interaction and fun (Watson, 2020). Secondary age children learn best through interpersonal approaches with discussions in groups and interaction with other students (Darling-Hammond et al, 2019).

Multiple measures for reducing physical contact are being used to reduce transmission including "moving classes outdoors, building additional classrooms, staggering start/end times, alternating shifts/days, hiring additional teachers to reduce class size, blending distance and inperson learning, and isolating class groupings from one another" (UNICEF, 2020b, p3). It is recommended that students and teachers keep 1 metre apart (WHO, UNESCO \& UNICEF, 2020). Painting or taping lines on the floor is useful where children line-up or gather (WASH in Schools Network, 2020a). Use of physical distancing cues have been reported in Bangladesh, Madagascar, and Senegal including marking the ground, and arranging seating (UNICEF, 2020b).

Mixing of classes for school and after-school activities should be limited (WHO, UNESCO \& UNICEF, (2020b). Contact can be reduced by cancelling assemblies and sports games (Watson, 2020). One-way systems also reduce interaction. Teachers should model and teach distancing.

Ventilation should be improved to maximise total airflow supply (WHO, UNESCO \& UNICEF, 2020). Decisions on mask use should follow national guidelines and advice on mask-wearing among children (UNICEF \& WHO, 2020b). Children under 5 are advised not to wear masks. 
Contact tracing should be in line with national policies and local health authorities (Watson, 2020). Schools must encourage students and school staff showing key symptoms to get tested. Thermometers for testing temperatures should be stocked in schools if possible, to help identify cases, and must be cleaned with rubbing alcohol between uses (Global Education Cluster, 2020). If symptoms develop during school hours that person must be separated and without causing stigma. Staff and students must be encouraged to stay at home if a family member is showing symptoms. And must stay at home for 14 days when a family member tests positive.

Flexibility in local decision making and clear protocols for re-closure help to limit spread (UNICEF, 2020b). Simplifying the curriculum is recommended to help deal with continued uncertainty. Teachers and school staff should be supported to help manage the psychosocial needs of students. To ensure a safe return that is accepted widely there must be early and regular communications for teachers, parents, and students (UNICEF, 2020b).

Emerging lessons for school return from UNICEF (2020b) include prioritising early grades and exam-preparatory classes for physical return to reduce negative effects on academic trajectories whilst minimising physical interaction (eg. Tunisia, Sierra Leone, and Malawi).

UNICEF (2020b, p5) report that "specific measures can help to support girls' and other vulnerable groups' return to school". Return to school campaigns in Burkina Faso are raising awareness for girl's education and offering scholarships and school meals for the most vulnerable. Only high-income countries are listed as examples of where specific provisions for disabled students are included in re-opening guidelines in the UNICEF (2020b) report on lessons emerging from school re-opening.

UNICEF (2020b) report emerging activity supporting WASH in school reopening. China has recruited temporary teachers to support smaller class sizes. Rwanda has built more classrooms and recruited more teachers so that classes are less crowded. Staggering of school days, weeks, and breaks have been introduced in a number of countries including Afghanistan, Egypt, Madagascar, Namibia, Papua New Guinea, Philippines, Senegal, and Vietnam. The Ministry of Education in Somalia rolled out a tracking system for monitoring and identifying at risk students and closures required. 


\section{References}

Biran, A., Schmidt, W. P., Varadharajan, K. S., Rajaraman, D., Kumar, R., Greenland, K., Gopalan, E., Aunger, R. \& Curtis, V. (2014). Effect of a behaviour-change intervention on handwashing with soap in India (SuperAmma): a cluster-randomised trial. The Lancet Global Health, 2(3), e145-e154. https://www.sciencedirect.com/science/article/pii/S2214109X13701608

COVID-19 HygieneHub (2020). What have we learned about promoting hand hygiene during the COVID-19 pandemic? https://washem-guides.s3.eu-west-

2.amazonaws.com/supplementary/hygiene-hub_learning-brief_hand-hygiene-promotion_en.pdf

CDC. (2020). Public Health Guidance for Community-Related Exposure.

https://schools.forhealth.org/risk-reduction-strategies-for-reopening-schools/download/

Darling-Hammond, L., Flook, L., Cook-Harvey, C., Barron, B., \& Osher, D. (2020). Implications for educational practice of the science of learning and development. Applied Developmental Science, 24(2), 97-140. https://www.tandfonline.com/doi/full/10.1080/10888691.2018.1537791

Dreibelbis, R., Kroeger, A., Hossain, K., Venkatesh, M., \& Ram, P. K. (2016). Behavior change without behavior change communication: nudging handwashing among primary school students in Bangladesh. International journal of environmental research and public health, 13(1), 129. https://www.mdpi.com/1660-4601/13/1/129

GIZ \& Sustainable Sanitation Alliance (2020). WASHaLOT 3.0 Group Washing Facility. Fit for School. https://www.susana.org/_resources/documents/default/3-2898-7-1600764030.pdf

Global Education Cluster (2020). Safe Back to School: A Practitioner's Guide. Global Education Cluster \& Child Protection Global Protection Cluster.

https://resourcecentre.savethechildren.net/node/17551/pdf/gec_checklist_8.7.20_digital.pdf

Grover, E., Hossain, M. K., Uddin, S., Venkatesh, M., Ram, P. K., \& Dreibelbis, R. (2018). Comparing the behavioural impact of a nudge-based handwashing intervention to high-intensity hygiene education: a cluster-randomised trial in rural Bangladesh. Tropical medicine \& international health, 23(1), 10-25. https://onlinelibrary.wiley.com/doi/full/10.1111/tmi.12999

McMichael, C. (2019). Water, sanitation and hygiene (WASH) in schools in low-income countries: A review of evidence of impact. International journal of environmental research and public health, 16(3), 359. https://pubmed.ncbi.nlm.nih.gov/30696023/

Philippines Department of Education (2018). Hygiene. How to reach the stars.

https://wins.deped.gov.ph/wp-content/uploads/2019/10/TSA-WinS-Booklet-Hygiene-FINAL-WEB20181031.pdf

Save the Children (2020a). School and household hygiene COVID-19 guidance.

https://resourcecentre.savethechildren.net/sites/default/files/documents/6_hygiene_covid-

19_guidance_v3_en.docx

Also available in French:

https://resourcecentre.savethechildren.net/sites/default/files/documents/6_hygiene_covid-

19_guidance_v3_fr.docx 
Save the Children (2020b). Kit 3: Essential COVID-19 Return to School WASH.

https://resourcecentre.savethechildren.net/sites/default/files/documents/3_covid_19_returning_to _school_kit_v3_en.docx

Also available in French:

https://resourcecentre.savethechildren.net/sites/default/files/documents/3_covid_19_returning_to _school_kit_v3_fr.docx

UNICEF (2020a). In-person schooling and COVID-19 transmission: a review of the evidence. https://www.unicef.org/media/89046/file/In-person-schooling-and-covid-19-transmission-reviewof-evidence-2020.pdf

UNICEF (2020b). Supplement to Framework for reopening schools: Emerging lessons from country experiences in managing the process of reopening schools.

https://www.unicef.org/media/83026/file/Emerging-lessons-from-countries-experiences-ofreopening-schools-2020.pdf

UNICEF (2020c). COVID-19 Emergency Preparedness and Response WASH and Infection Prevention and Control Measures in Schools. https://www.unicef.org/media/66356/file/WASHCOVID-19-infection-prevention-and-control-in-schools-20

UNICEF \& GIZ (2016). Scaling up group handwashing in schools. Compendium of group washing facilities across the globe. http://www.fitforschool.international/wpcontent/ezdocs/giz_unicef_Catalogue_WashingFacilities_FINAL_WEB_new.pdf

UNICEF \& GIZ (2013). Field Guide: The Three Star Approach for WASH in Schools. United Nations Children's Fund and Deutsche Gesellschaft für Internationale Zusammenarbeit (GIZ), Eschborn, Germany. https://www.susana.org/_resources/documents/default/2-1839-field-guidethree-star-approach-for-washinschoolsdraft201308231.pdf

UNICEF \& WHO (2020a). Progress on drinking water, sanitation and hygiene in schools. Special focus on COVID-19. https://washdata.org/sites/default/files/2020-08/jmp-2020-wash-schools.pdf

UNICEF \& WHO (2020b). Advice on the use of masks for children in the community in the context of COVID-19. https://www.who.int/publications/i/item/WHO-2019-nCoV-IPC_MasksChildren-2020.1

WASH in Schools Network (2020a). 10 immediate WASH in schools (WinS) actions. https://globalhandwashing.org/wp-content/uploads/2020/07/10-WinS-Actions-COVID-19.pdf

WASH in Schools Network (2020b). WASH in Schools and Coronavirus. Safe reopening of schools. https://www.susana.org/_resources/documents/default/3-3831-7-1590761512.pdf

WASH in Schools Network (2020c). WASH in Schools Checklists to Manage COVID-19 Response - Checklists for school entrances, classrooms \& toilets.

https://www.susana.org/en/knowledge-hub/resources-and-publications/library/details/3893

WaterAid (2020). Technical Brief On Contactless Handwashing stations.

https://www.wateraid.org/sites/g/files/jkxoof271/files/2020-04/wateraid-nepal-technical-briefcontactless\%20handwashing-stations.pdf 
Watson, J. (2020). Summary report on COVID-19 control strategies for opening schools. Summary of key insights from the WINS network.

https://resources.hygienehub.info/en/articles/4101789-summary-report-on-covid-19-controlstrategies-for-opening-schools

Watson, J. \& Dreibelbis, R. (2020). Using environmental nudges to improve handwashing with soap among school children. WASH in Schools Network.

https://www.comminit.com/files/winsnudgescovid-19_final_web-2.pdf

Watson, J., Dreibelbis, R., Aunger, R., Deola, C., King, K., Long, S., Chase, R.P. \& Cumming, O. (2019). Child's play: harnessing play and curiosity motives to improve child handwashing in a humanitarian setting. International journal of hygiene and environmental health, 222(2), 177-182. https://www.sciencedirect.com/science/article/pii/S1438463918305686

White, S., Thorseth, A. H., Dreibelbis, R., \& Curtis, V. (2020). The determinants of handwashing behaviour in domestic settings: an integrative systematic review. International Journal of Hygiene and Environmental Health, 227, 113512.

https://www.sciencedirect.com/science/article/pii/S1438463919311101

WHO (2020). What we know about COVID-19 transmission in schools. The latest on the COVID19 global situation \& the spread of COVID-19 in schools. https://www.who.int/docs/defaultsource/coronaviruse/risk-comms-updates/update39-covid-and-schools.pdf?sfvrsn=320db233_2

WHO, UNESCO \& UNICEF (2020). Considerations for school-related public health measures in the context of COVID-19. Annex to Considerations in adjusting public health and social measures in the context of COVID-19. https://www.who.int/publications/i/item/considerations-forschool-related-public-health-measures-in-the-context-of-covid-19

\section{Acknowledgements}

We thank the following experts who voluntarily provided suggestions for relevant literature or other advice to the author to support the preparation of this report. The content of the report does not necessarily reflect the opinions of any of the experts consulted.

- Christie Chatterley, Fort Lewis College

- Irene Amongin, UNICEF

- Bella Monse, GIZ

- Matthew Freeman, Rollins School of Public Health

\section{Suggested citation.}

Bolton, L. (2021). WASH in schools for student return during the COVID-19 pandemic. K4D Helpdesk Report 969. Brighton, UK: Institute of Development Studies. DOI: 10.19088/K4D.2021.024 


\section{About this report}

This report is based on six days of desk-based research. The K4D research helpdesk provides rapid syntheses of a selection of recent relevant literature and international expert thinking in response to specific questions relating to international development. For any enquiries, contact helpdesk@k4d.info.

K4D services are provided by a consortium of leading organisations working in international development, led by the Institute of Development Studies (IDS), with Education Development Trust, Itad, University of Leeds Nuffield Centre for International Health and Development, Liverpool School of Tropical Medicine (LSTM), University of Birmingham International Development Department (IDD) and the University of Manchester Humanitarian and Conflict Response Institute (HCRI).

This report was prepared for the UK Government's Foreign, Commonwealth and Development Office (FCDO) and its partners in support of pro-poor programmes. Except where otherwise stated, it is licensed for non-commercial purposes under the terms of the Open Government License v3.0. K4D cannot be held responsible for errors, omissions or any consequences arising from the use of information contained in this report. Any views and opinions expressed do not necessarily reflect those of FCDO, K4D or any other contributing organisation.

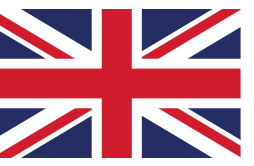

(C) Crown copyright 2021. 